\title{
DNA bending as a potential regulatory cis-acting element of the geminivirus intergenic region
}

\author{
C Gutiérrez *, P Suárez-López, E Ramírez-Parra, A Sanz-Burgos, J Pönninger, Q Xie
}

Centro de Biologia Molecular 'Severo Ochoa' (CSIC-UAM), Universidad Autónoma de Madrid, Cantoblanco, E-28049 Madrid, Spain

(Received 20 May 1995; accepted 4 July 1995)

\begin{abstract}
Summary - Geminiviruses constitute a unique group of plant DNA viruses which produce important diseases both in mono- and dicotyledonous plants throughout the world. In particular, several members of the geminivirus subgroup I infect, among others, wheat (wheat dwarf virus, WDV), maize (maize streak virus, MSV) or different species of grasses. We are interested in identifying regions within the control region of the geminivirus genome which may act as regulatory elements during viral DNA replication and/or transcription. Recently, we have studied the DNA structure of the WDV large intergenic region by 2-dimensional polyacrylamide gel electrophoresis and by electron microscopy, and we have characterized a previously unidentified DNA sequence which confers intrinsic DNA bending properties. Here, we extend this study to other members of the subgroup I (SI) geminiviruses, in particular MSV. In general, DNA curvature was conferred by the presence of A-tracts separated by an integral number of helical turns. DNA bending within the regulatory regions of SI geminivirus DNA appears to be a common, though not general, situation. The possible implications of DNA bending of WDV as well as other SI geminivirus DNA as a regulatory element of viral DNA replication and/or transcription will be discussed in relation to the known effects of DNA curvature in other prokaryotic and eukaryotic replicons.
\end{abstract}

geminivirus / DNA bending / DNA replication / rolling-circle / monocotyledon

Résumé - Courbure de l'ADN comme élément de régulation agissant en cis de la région intergénique des géminivirus. Les géminivirus sont constitués d'un groupe singulier de virus de plantes à $A D N$, qui provoquent des maladies importantes chez les mono- et chez les dicotylédones dans le monde entier. En particulier, plusieurs membres du sous-groupe 1 infectent, entre autres, le blé (virus du nanisme du blé, WDV), le maïs (virus du streak du maïs, MSV), ou diverses espèces de poacées. Nous nous sommes intéressés à l'identification de régions incluses dans la région de contrôle du génome des géminivirus qui pourraient agir comme éléments de régulation pendant la réplication et/ou la transcription virale. Récemment, nous avons étudié la structure de I'ADN de la grande région intergénique du WDV par électrophorèse bidimensionnelle en gel de polyacrylamide, et par microscopie électronique, et nous avons caractérisé une séquence d'ADN, non identifiée jusque là, qui confère des propriétés intrinsèques de courbure de l'ADN. Dans le présent travail, nous avons étendu cette étude à d'autres membres du sous-groupe 1(S1) des géminivirus, en particulier au MSV. En général, la courbure de l'ADN était conférée par la présence de segments polyA, séparés par un nombre entier de tours d'hélice. La courbure de I'ADN dans les régions de régulation des géminivirus $\mathbf{S 1}$ semble être une situation courante, sinon générale. Les implications possibles de la courbure de l'ADN du WDV

\footnotetext{
* Correspondence and reprints
} 
aussi bien que de celui d'autres géminivirus $S 1$, comme éléments de régulation potentiels de la réplication et/ou de la transcription de l'ADN viral, seront discutées en relation avec les effets connus de la courbure de l'ADN chez d'autres replicons procaryotiques ou eucaryotiques.

géminivirus / courbure de l'ADN / réplication de l'ADN / cercle courant / monocytolédones

\section{INTRODUCTION}

Geminiviruses constitute a unique group of plant DNA viruses which infect both mono- and dicotyledonous plants and produce, in many cases, significant reductions in important crops all over the world. Several features of the molecular biology of these eukaryotic DNA viruses make them a very attractive model system to understand how the infectious process takes place as well as to study DNA replication in higher plant cells. A detailed knowledge of the geminivirus molecular biology is necessary before we can use this basic information for the rational design of non-coventional strategies for virus control and for the construction of gene expression vectors for plant cells (Stanley, 1993).

Geminiviruses are characterized by (i) their unique twinned quasi-icosahedral particles; (ii) their small genomes composed of 1 (monopartite) or 2 (bipartite) circular single-stranded DNA (ssDNA) molecules of $\sim 2600-3000 \mathrm{~kb}$; (iii) their replication process, which occurs entirely in the nucleus of the host cell via rolling-circle intermediates; and (iv) the small number of virally encoded proteins, thereby both viral DNA replication and transcription must rely largely on host proteins (see Davies and Stanley, 1989; Lazarowitz, 1992, for review). In all cases studied so far, transcription of geminivirus DNA occurs bidirectionally and is directed by 2 divergent promoters (MorrisKrsinich et al, 1985; Townsend et al, 1985). This genetic organization defines an intergenic region of about $200-400 \mathrm{bp}$. In the case of monocotinfecting geminiviruses, which belong to the subgroup I (SI; Rybicki, 1994), this non-transcribed region is called large intergenic region (LIR), to distinguish it from another small intergenic region (SIR), located $180^{\circ}$ from the LIR and required for accumulation of viral DNA (Kamman et al, 1991). In addition to transcriptional control elements, the LIR contains cis-acting elements required for viral DNA replication (Kammann et al, 1991; Hofer et al, 1992). Recently, the initiation site for rolling-circle DNA replication has been mapped within the conserved nonanucleotide sequence present in all the geminiviruses sequenced so far (HeyraudNitschke et al, 1995; Stanley, 1995).
A modular organization of the intergenic region of tomato golden mosaic virus (TGMV), a bipartite, dicot-infecting geminivirus belonging to the subgroup III (SIII), has been proposed and is characterized by the initiation site for rolling-circle DNA replication and by a binding site for the replicationassociated (Rep) protein (Fontes et al, 1994). Direct evidence for the presence of a similar cisacting signal in monocot-infecting geminiviruses is still lacking. However, the presence of inverted repeats, which may be involved in the interaction with viral (and/or cellular) proteins has recently been noted (Argüello-Astorga et al, 1994).

To identify cis-acting signals in the LIR of geminivirus DNA, we have looked for the presence of intrinsic (also called static) DNA curvature, since this particular DNA structure has been shown to be necessary in a number of systems for origin activity, eg, bacteriophage $\lambda$ (Zahn and Blattner, 1985) or for transcription regulation (Kerppola and Curran, 1991; Pérez-Martín et al, 1994). In this work, we report our results on DNA curvature in members of the monocot-infecting SI geminiviruses in comparison to other well-characterized eukaryotic DNA replicons. The possible significance of DNA curvature in the regulatory region of geminivirus DNA on viral functions such as DNA replication and/or transcription will be discussed.

\section{MATERIALS AND METHODS}

\section{DNA manipulations}

Restriction endonucleases and other enzymes for DNA manipulations were from Boehringer Mannheim, New England Biolabs and Promega. Unlabeled deoxynucleotides were from Pharmacia. Standard DNA manipulation techniques were applied as described in Sambrock et al (1989).

\section{Two-dimensional polyacrylamide gel electrophoresis}

The procedure used was essentially as described by Mizuno (1987). DNA samples were run in the first 
dimension on a $5 \%$ polyacrylamide gel in TBE buffer at $5 \mathrm{~V} / \mathrm{cm}$ at $60^{\circ} \mathrm{C}$. The gel was then rotated $90^{\circ}$ relative to the first dimension and the temperature was equilibrated to $4^{\circ} \mathrm{C}$. The second dimension was run under the same conditions except that the temperature was maintained at $4^{\circ} \mathrm{C}$. DNA fragments were visualized by staining the gel with $0.5 \mu \mathrm{g} / \mathrm{ml}$ ethidium bromide.

\section{RESULTS AND DISCUSSION}

One of the simplest and most reliable methods to determine whether a short piece of DNA contains a static curvature is the analysis of the electrophoretic behavior of restriction fragments after 2-dimensional polyacrylamide gel electrophoresis (2D-PAGE), as described initially by Mizuno (1987). As outlined in figure 1A, after digestion with restriction endonucleases to produce a convenient set of DNA fragments, the first dimension took place at $60^{\circ} \mathrm{C}$. Under these conditions, DNA fragments were fractionated according to their sizes since anomalous migration due to shape was minimized. After rotation of the gel by $90^{\circ}$, the second dimension occurred at $4^{\circ} \mathrm{C}$, which served to increase the effect of shape. As a result, non-curved DNA fragments will show the same mobility in both dimensions and, therefore, they will appear in the diagonal of the gel. in contrast, DNA fragments containing an intrinsic curvature will move more slowly in the second dimension and will thus deviate from the diagonal. An example of such an analysis is shown in figure $1 \mathrm{~B}$ for the case of restriction fragments derived from a wheat dwarf virus (WDV) clone. Two fragments clearly deviate from the diagonal: an internal marker, known to be bent (fig 1B, open arrowhead) and a DNA fragment containing the entire WDV LIR (fig 1B, closed arrowhead). A similar analysis was carried out for a mixture of restriction DNA fragments derived from a maize streak virus (MSV, another member of the SI geminivirus family) clone (fig $1 \mathrm{C}$ ). In this case, a DNA fragment containing the MSV LIR (fig 1C, closed arrowhead) also separates from the diagonal of non-curved DNA fragments, indicating the presence of a static DNA curvature within it. A more detailed analysis of DNA bending within the WDV LIR, including the mapping of the DNA bending center by electron microscopy and circular permutation analysis (Wu and Crothers,
Fig 1. Analysis of DNA curvature of geminivirus LIR by 2-dimensional polyacrylamide gel electrophoresis. A. Outline of the experimental protocol used. B. A sample of plasmid pWDV4GUS, containing WDV sequences, was digested to produce a set of restriction fragments of which the 580 bp EcoRI-BamHI fragment contains the WDV LIR. This sample was mixed with HindlIIdigested phage $\varphi 29$ DNA used as marker. The mixture was fractionated by 2D-PAGE as described in Materials and methods. Arrowheads point to bent DNA fragments from the marker (open) and the WDV sample (closed). C. A similar analysis was carried out with DNA fragments derived from plasmid pMSV7N4D, containing MSV sequences, after digestion with $\mathrm{BamHI}$ and $\mathrm{Bst} B \mathrm{BI}$ restriction endonucleases. Marker DNA and symbols are as in $B$. In this case the diagonal of non-bent DNA fragments has been highlighted with a white line.

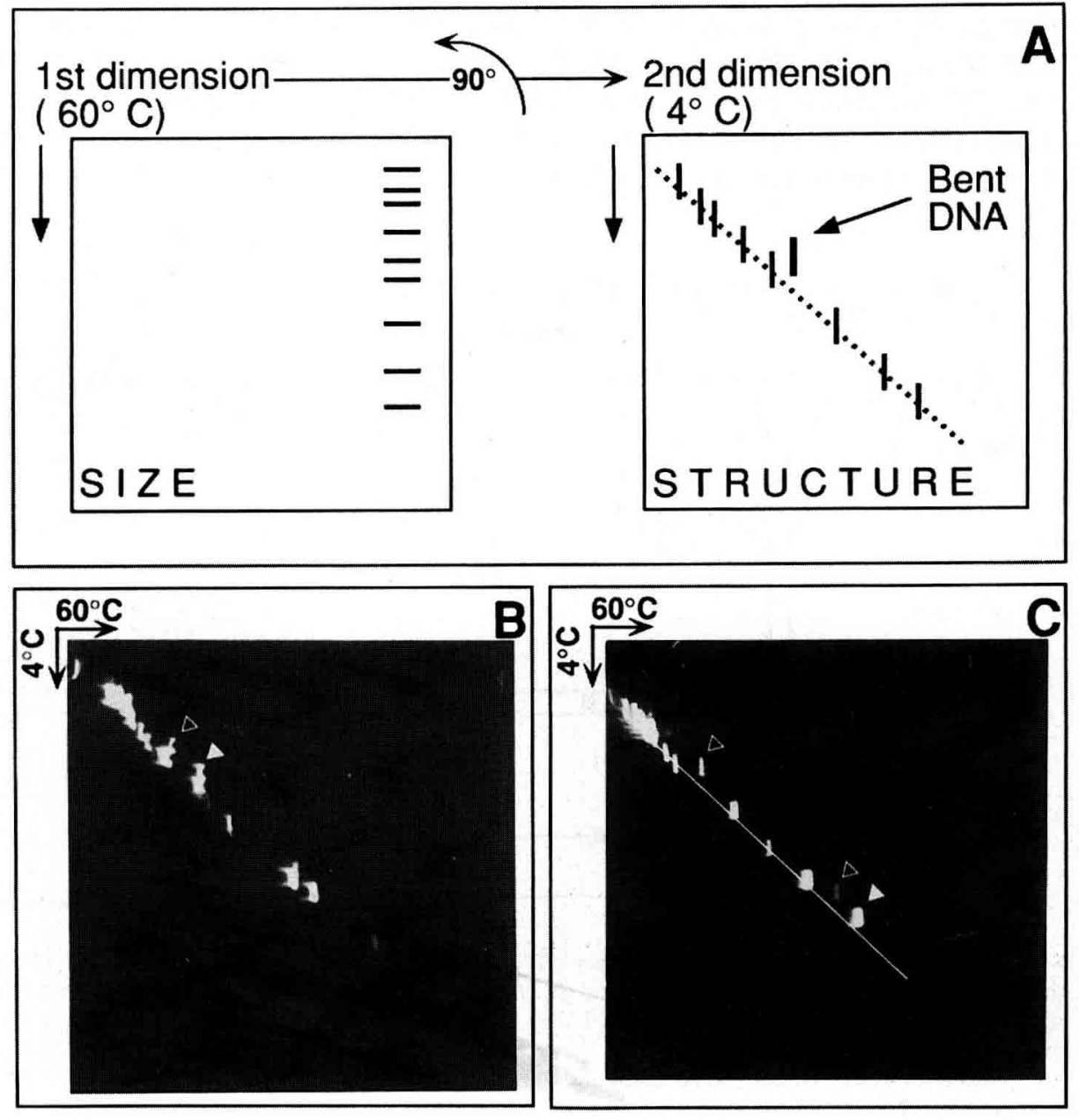


1984), has recently been published (SuárezLópez et al, 1995).

Intrinic DNA bending is normally associated with the presence of a series of tracts of 3-4 adenine residues, each separated from the next by an integral number of helical turns (reviewed in Crothers et al, 1990). As shown in figure 2, this is the case for the WDV LIR, where the bending lies on a region with phased A-tracts, called A1 through A6 (Suárez-López et al, 1995). A closer inspection of the DNA sequence revealed that tracts A1 through A4 (fig 2, vertical black bars), but not $A 5$ and $A 6$ (fig 2, vertical grey bars), coincide precisely with the DNA helical repeat (10-11 nt per turn). This spatial organization may suggest the presence of a more complex DNA curvature formed by 2 different bent regions: one constituted by tracts $A 1$ through $A 4$, towards the site for initiation of DNA replication, and the other formed by tracts $A 5$ and $A 6$, just upstream from the TATA box. If this is the case, the experimentally determined bending center would be the result of both bent regions, although this issue will be addressed in the future. It is worth noting that the presence of phased A-tracts, located between the initiation site for rolling-circle DNA replication and the TATA-box for late viral gene expression, appears to be a common feature in most members of the geminivirus SI, in which only Chloris striate-mosaic virus (CSMV) and Miscanthus streak virus (MiSV) seem to lack phased A-tracts in their LIRs (Ramírez and
Gutiérrez, in preparation). Therefore, it might be that a bent DNA region is a constitutive structural element of the SI geminivirus LIR, as it is the case in well-characterized plasmids such as pT181 (Koepsel and Kahn, 1986), pLS1 (PérezMartín et al, 1988) and pC194 (Gros et al, 1987), and animal virus and cellular replicons (Caddle et al, 1990; Hernández et al, 1993; DePamphilis, 1993). This observation is in agreement with the modular organization proposed for SIll geminiviruses (Fontes et al, 1994).

As mentioned above, the presence of a bent DNA region between the initiation site for DNA replication and the TATA-box may play a functional role at different levels during either viral DNA replication or transcription. First, stabilization of a nucleoprotein complex could depend on the presence of a bent DNA region as described in other systems (Koepsel and Kahn, 1986; Stenzel et al, 1987; Pérez-Martín et al, 1994). In these cases, an increase in DNA bending frequently occurs upon complex formation. Whether this is the case at the SI geminivirus LIR must be determined in the future. Something that has to be kept in mind is that association of viral protein(s) with the LIR may be mediated by cellular proteins which can be targeted to the bent DNA region. Analysis of this possibility will open a completely new avenue in geminivirus molecular biology and may contribute to the identification of cellular proteins required for viral functions. Second, it has been shown that the double-

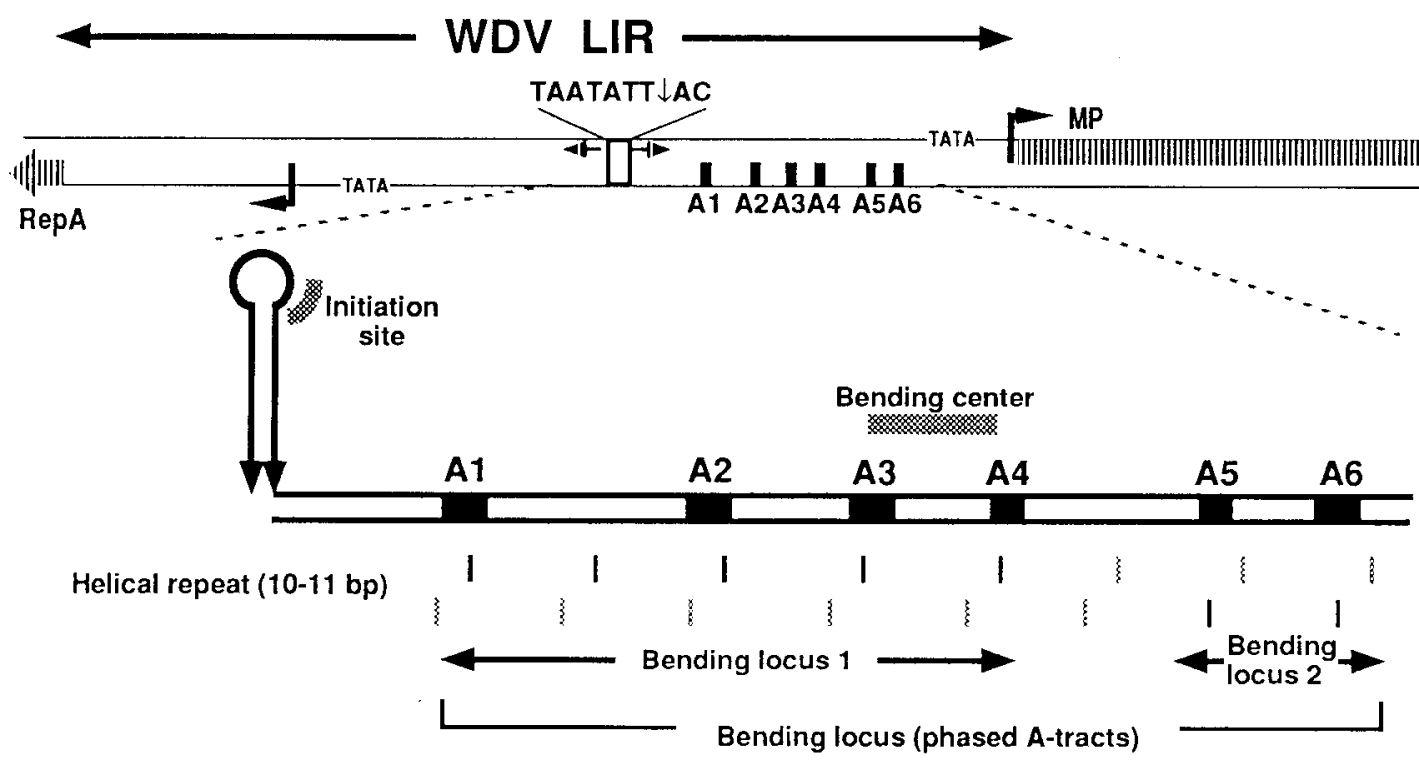

Fig 2. Localization of phased A-tracts within WDV LIR between the initiation site of double-stranded DNA replication and late gene transcription. Landmarks in this region of the WDV genome include the 19-bp inverted repeats $(-\square)$, which have the potential to form a stem-loop structure, the 9-bp TAATATT $\downarrow$ AC (vertical arrow indicates the initiation site of double-stranded DNA replication) sequence located between the repeats $(\bigsqcup)$, and the A-tracts ( $\mathbf{H}$, A through $A 6)$. Initiation sites ( $\longrightarrow$ ) for both early and late transcription (Dekker et al, 1991), the TATA boxes and the $5^{\prime}$ proximal portions of RepA and movement protein (MP) (..lil) are also indicated. In the lower part, the DNA helical repeat (10-11 nucleotides) has been also included. See text for details. 
stranded DNA forms of the geminivirus genome associate with histones to form minichromosomes whose structure is indistinguishable from the host cell chromatin (Abouzid et al, 1988; Pilartz and Jeske, 1992). Therefore, the presence of a bent DNA region within the LIR could also play its role by preventing repression by chromatin structure of either the DNA replication origin activity or the late gene transcription, as it has been demonstrated to occur in polyoma virus (Martínez-Salas et al, 1989).

In summary, the presence of a bent DNA region seems to be a common feature of the structural organization of the LIR within SI geminivirures. The assembly of a nucleoprotein structure with the participation of the viral Rep protein, and likely cellular trans-acting factors, at the geminivirus LIR may contribute to one or more stages during viral DNA replication and/or transcription. The bent DNA region may have a role in facilitating the formation of such complexes, in their stabilization or their activity, as well as in preventing repression of viral functions by the presence of nucleosomes in the LIR. Clearly, our observations simply serve to pose interesting possibilities that will have to be addressed experimentally in the future and that will contribute to a better understanding of the geminivirus molecular biology, a step absolutely necessary before we can take advantage of that knowledge for practical applications in infection control and expression vector design.

\section{ACKNOWLEDGMENTS}

The authors are indebted to PM Mullineaux (John Innes Institute, UK) and C Fenoll (Universidad Autónoma de Madrid) for plasmids pWDV4GUS and pMSV7N4D, respectively. This work was supported by grants PB93-0128 from the Dirección General de Investigación Científica y Técnica and $\mathrm{Cl}_{1}{ }^{*}$-CT94-0079 from the European Community. The institutional support of Fundación Ramón Areces to the Centro de Biología Molecular "Severo Ochoa" is also acknowledged.

\section{REFERENCES}

Abouzid AM, Frischmuth T, Jeske H (1988) A putative replicative form of the abutilon mosaic virus (gemini group) in a chromatin-like structure. Mol Gen Genet $212,252-258$

Argüello-Astorga GR, Guevara-González RG, HerreraEstrella LR, Rivera-Bustamante RF (1994) Geminivirus replication origins have a group-specif- ic organization of iterative elements: a model for replication. Virology 203, 90-100

Caddle MS, Dailey L, Heintz NH (1990) RIP60, a mammalian origin-binding protein, enhances DNA bending near the dihydrofolate reductase origin of replication. Mol Cell Biol 10, 6236-6243

Crothers DM, Haran TE, Nadeau JG (1990) Intrinsically bent DNA. J Biol Chem 265, 7093-7096

Davies JW, Stanley J (1989) Geminivirus genes and vectors. Trends Genet 5, 77-81

Dekker EL, Woolston CJ, Xue Y, Cox B, Mullineaux PM (1991) Transcript mapping reveals different expression strategies for the bicistronic RNAs of the geminivirus wheat dwarf virus. Nucleic Acids Res $19,4075-4081$

DePamphilis ML (1993) Eukaryotic DNA replication: anatomy of an origin. Annu Rev Biochem 62, 29-63

Fontes EPB, Gladfelter HJ, Schaffer RL, Petty ITD, Hanley-Bowdoin L (1994) Geminivirus replication origins have a modular structure. Plant Cell 6, 405-416

Gros MF, te Riele H, Ehrlich SD (1987) Rolling circle replication of single-stranded DNA plasmid pC194. EMBO J 6, 3863-3869

Hernández $\mathrm{P}$, Martín-Parras L, Martínez-Robles ML, Schvartzman JB (1993) Conserved features in the mode of replication of eukaryotic ribosomal RNA genes. EMBO J 12, 1475-1485

Heyraud-Nitschke F, Schumacher S, Laufs J, Schaefer S, Schell J, Gronenborn B (1995) Determination of the origin cleavage and joining domain of geminivirus Rep proteins. Nucleic Acids Res 23, 910-916

Hofer JM, Dekker EL, Reynolds HV, Woolston CJ, Cox BS, Mullineaux PM (1992) Coordinate regulation of replication and virion sense gene expression in wheat dwarf virus. Plant Cell 4, 213-223

Kammann M, Schalk HJ, Matzeit V, Schaefer S, Schell J, Gronenborn B (1991) DNA replication of wheat dwarf virus, a geminivirus, requires 2 cis-acting signals. Virology 184, 786-790

Kerppola TK, Curran T (1991) DNA bending by Fos and Jun: the flexible hinge model. Science 254 , 1210-1214

Koepsel RR, Khan SA (1986) Static and initiator protein-enhanced bending of DNA at a replication origin. Science 233, 1316-1318

Lazarowitz S (1992) Geminiviruses: genome structure and gene function. Crit Rev Plant Sci 11, 327-349

Martínez-Salas E, Linney E, Hassell J, DePamphilis ML (1989) The need for enhancers in gene expression first appears during mouse development with formation of the zygotic nucleus. Genes Dev 3, 1493-1506

Mizuno T (1987) Random cloning of bent DNA segments for Escherichia coli chromosome and primary characterization of their structures. Nucleic Acids Res 15, 6827-6841

Morris-Krsinich BAM, Mullineaux PM, Donson J et al (1985) Bidirectional transcription of maize streak virus DNA and identification of the coat protein gene. Nucleic Acids Res 13, 7237-7256 
Pérez-Martín J, del Solar GH, de la Campa AG, Espinosa M (1988) Three regions in the DNA of plasmid pLS1 show sequence-directed static bending. Nucleic Acids Res 16, 9113-9126

Pérez-Martín J, Rojo F, de Lorenzo V (1994) Promoters responsive to DNA bending: a common theme in prokaryotic gene expression. Bacteriol Rev 58, 268-290

Pilartz M, Jeske H (1992) Abutilon mosaic geminivirus double-stranded DNA is packed into minichromosomes. Virology $189,800-802$

Rybicki EP (1994) A phylogenetic and evolutionary justification for 3 genera of geminiviridae. Arch Virol $139,49-77$

Sambrook J, Fritsch EF, Maniatis T (1989) Molecular Cloning: A Laboratory Manual, Cold Spring Harbor Laboratory Press, Cold Spring Harbor, NY, USA

Stanley J (1993) Geminiviruses: plant viral vectors. Curr Opin Genet Dev 3, 91-96

Stanley J (1995) Analysis of African cassava mosaic virus recombinants suggests strand nicking occurs within the conserved nonanucleotide motif during the initiation of rolling circle DNA replication. Virology 206, 707-712

Stenzel TT, Patel P, Bastia D (1987) The integration host factor of Escherichia coli binds to bent DNA at the origin of replication of the plasmid pSC101. Cell $49,709-717$

Suárez-lópez $P$, Martínez-Salas $E$, Hernández $P$, Gutiérrez C (1995) Bent DNA in the large intergenic region of wheat dwarf geminivirus. Virology 208 , 303-311

Townsend R, Stanley J, Curson SJ, Short MN (1985) Major polyadenylated transcripts of cassava latent virus and location of the gene encoding coat protein. EMBO J 4, 33-37

Wu HM, Crothers DM (1984) The locus of sequencedirected and protein-induced DNA bending. Nature (Lond) 308, 509-513

Zahn K, Blattner FR (1985) Sequence-directed DNA curvature at the bacteriophage $\lambda$ origin of replication. Nature (Lond) 317, 451-453 